\title{
Undergraduate Robotics Education in Technologically Underserved Communities
}

\author{
M. Bernardine Dias, Brett Browning, G. Ayorkor Mills-Tettey, \\ Nathan Amanquah, and Noura El-Moughny
}

\begin{abstract}
This paper addresses the challenges and benefits of undergraduate robotics education in technologically underserved communities. We present two robotics courses that the authors designed and taught in Qatar and Ghana. While different in context and setting, these courses share a similar structure and approach. We describe and analyze our experiences in the two case studies, and extract lessons that are relevant to others teaching robotics; especially in underserved communities. We also address the impact of these courses on the local communities and the broader academic community.
\end{abstract}

\section{INTRODUCTION}

$\mathrm{T}_{\mathrm{r}}$ HE demand for technology education and research is rapidly growing in technologically underserved communities around the world ([8], [1], [5], [6]). This demand stems from the need for sustainable, relevant and accessible technology that is culturally and economically suitable in these communities. In response to these needs, this paper presents two case studies of robotics education in communities where computing technology is in its early stages of impact. These courses aim to empower younger generations to become creators of innovative technology solutions to problems in their communities, and knowledgeable consumers of computing technology. An important motivation for teaching robotics in technologically underserved communities is its multidisciplinary nature and its ability to excite and inspire students to be creative ([11], [12]). Hands-on projects expose students to the challenges, joys and frustrations of systems development and integration. The experience of observing their implementations in action is uniquely motivating and empowering to students. For these reasons, robotics plays a powerful role in technology education and

Manuscript received September 15, 2006. This work was supported in part by the Qatar Foundation for Education, Science, and Community Development, the Berkman Faculty Development Fund at Carnegie Mellon University, and Ashesi University.

The first two authors have joint faculty appointments at Carnegie Mellon University campuses in Pittsburgh and Doha (email: \{mbdias, brettb (a)ri.cmu.edu). The third author is a Ph.D. candidate at Carnegie Mellon University in Pittsburgh and was a visiting lecturer at Ashesi University in Ghana (email: ayorkor@cmu.edu). The fourth author is faculty at Ashesi University in Ghana (email: namanquah@ashesi.edu.gh). The fifth author is an undergraduate at Carnegie Mellon University in Doha (email: nelmough@qatar.cmu.edu). in motivating students to become technical experts in their communities. Advanced robotics courses can also expose students to the excitement and value of state-of-the-art research. This exposure has the added benefit of connecting the students to their peers around the world, thus relieving the isolation often experienced by these students.

While tremendous benefit results from technology education in underserved communities, implementing relevant courses is non-trivial and several challenges must be addressed. One of the most important challenges is the limited availability of the necessary equipment, mechanical and electrical components, and tools required for robotics projects. Addressing cultural perceptions and fears of technology can also provide interesting challenges when designing appropriate courses. Intellectually, the biggest challenge is in mapping classroom experiences to projects and concepts of local relevance. In some technologically underserved communities, cost can also be a concern since many of the available robotics kits tend to be outside the price range of local universities, and sometimes even computers are prohibitively expensive. Training and hiring technology educators and maintaining technical equipment can be a further challenge in many of these communities.

Despite these many challenges, technology education in underserved communities is an important endeavor that is gaining momentum ([1], [2], [7], [8], [9], [13]). While addressing all of the challenges is important, the work presented in this paper focuses on undergraduate robotics education in technologically underserved communities with access to computing infrastructure. Our goal is to inspire more robotics and related educational endeavors in similar communities by sharing the successes, limitations, and lessons learned in two relevant case studies.

In the next section we describe the two case studies, one in Qatar and one in Ghana that form the basis of this paper. We then examine their similarities and differences, and highlight lessons learned that are widely applicable. The broader impact of the two cases is investigated next, followed by future directions and conclusions for this work.

\section{CASE Study In QATAR}

Education City, sponsored by the Qatar Foundation [10], is located on the outskirts of Doha, Qatar. It is a unique 
endeavor that includes departments from some of the world's leading universities, in addition to a primary school, a high school, and several other bridging educational and research institutions. In this paper, we focus on the Computer Science (CS) Department of Carnegie Mellon University in Qatar (CMU-Q), which opened in 2004 [9]. In the fall of 2005, the authors taught an introductory robotics course to 19 second year CS students, with 12 women and 7 men. 17 of these students completed this course titled "Autonomous Robots."

\section{A. Infrastructure and Preparation}

Prior to the course, the CMU-Q students had completed two introductory programming courses in Java, an introductory robotics course, and an introductory mathematics course. Concurrent to the Autonomous Robotics course, the students were completing an advanced course in algorithms and data structures and additional mathematics courses. Each student was provided with a US\$1500 Dell laptop to use as a dedicated machine for the semester, and with a US\$300 Evolution Robotics ER1 robot; a robot kit built with X-beam aluminum construction and with a low-cost web camera for sensing. The laptops were fully networked and installed with Linux. In addition, the students were given $\mathrm{C}++/$ Java software written by the authors that provided perception, tracking, and low-level motion control support, and a Java control program with a few example behaviors. The students had 24-hour access to laboratory space seven days a week.

\section{B. Autonomous Robots}

Primarily, this course aimed to introduce students to robotics and to teach them theoretical and practical skills in programming robots. A secondary goal of the course was to apply concepts the students learned in the CS courses in a laboratory setting. Last but not least, the course was designed to expose students to the world of research and to encourage them to become more creative technical thinkers. To achieve these objectives, the course was taught as two lectures and one lab session per week. Assessment was continuous and varied in order to encourage the students to learn the theoretical and practical components of the course material, as well as to think creatively. The assessment incorporated four laboratory assignments, five homework assignments, a mid-semester research project, and a final project. The laboratory assignments involved teams of two or three students, where new teams had to be formed for each new assignment, while the remainder of the work was individual. The mid-semester project required the students to meet with the librarian and writing staff, and to deliver an oral presentation and a written paper describing an on-going or past robotics research project of their choice. The final project required the students to develop and demonstrate a robotics technology solution to a problem of their choice, deliver an oral presentation describing their project, and write a paper reporting their work. Finally, to conclude the course, they prepared and presented posters about their final projects to peers, CMU-Q faculty and staff, family members, friends, and media representatives.

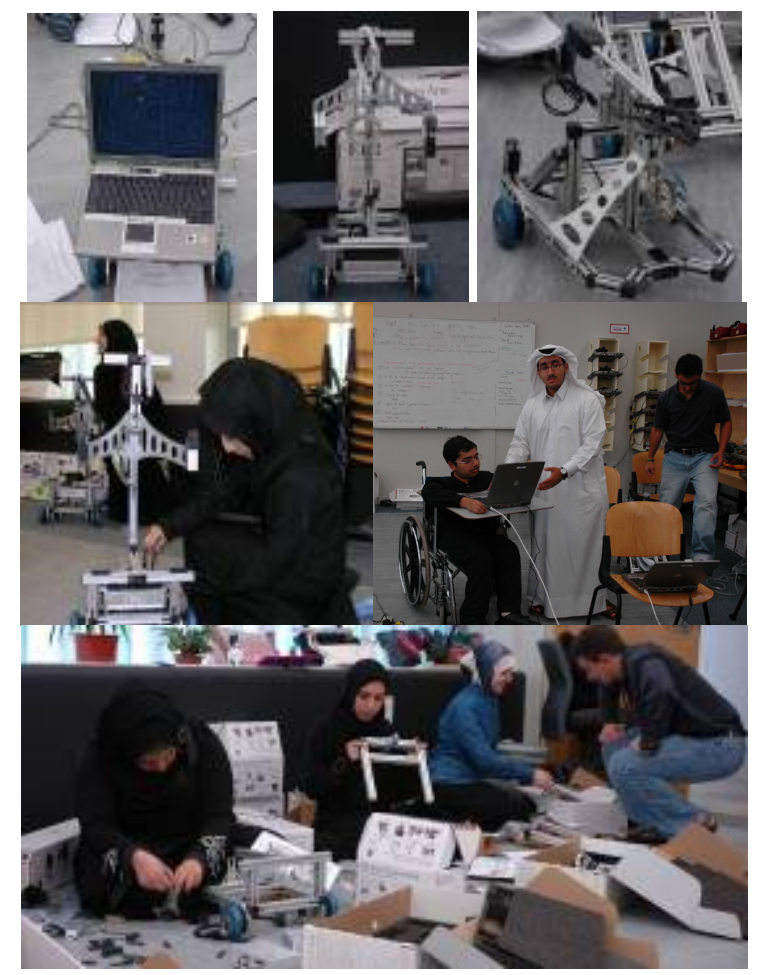

Figure 1: CMU-Q students working on a project and student-assembled robots

Lecture topics included kinematics, control, sensing and perception, path planning, machine learning, machine vision, manipulation, and team coordination. Some lectures were also dedicated to discussing on-going research in Robotics, and potential Robotics careers and applications in Qatar. The homework assignments followed the lecture material closely and were used to assess the students' understanding of theoretical concepts. The lab assignments required students to install Linux on their laptops and construct their robots from the kits, with a design of their choice, and then use these robots to implement several capabilities. These capabilities included a simple potential field reactive navigation system, a state-machine based behavioral controller to solve a simple game of knocking down blue fiducials, while spinning to 'identify' red ones, and a coordination mechanism to allow two robots to autonomously rotate and move a box a distance of $1 \mathrm{~m}$. These assignments were completed by mid-semester, and the remaining time was dedicated to the student's final projects. The final projects were formulated based on student interests and topics ranged from soccer-playing robots and robots responding to traffic signals, to entertainment and assistive robotic projects. Some projects focused on algorithms for path planning, while others emphasized the application of sensing and machine learning.

\section{CASE StUdy In GHANA}

Ashesi University [2] is a small private university established in 2002 in Accra that is emerging as a leader in 
computer science education in Ghana. Robotics, however, is a new topic for Ashesi where no engineering program is currently offered. Through a partnership with TechBridgeWorld [14] at Carnegie Mellon University, an introductory course in robotics and artificial intelligence (AI) was piloted during the summer of 2006. The course design was based on the authors' experience of teaching the "Autonomous Robots" course in Qatar. To our knowledge, this course titled "Introduction to Robotics and Artificial Intelligence" was the first undergraduate robotics course in Ghana. It aimed to enhance the students' technical creativity and problem solving abilities by engaging them in hands-on projects while introducing them to the exciting field of robotics. Another goal was to expand the students' perception of the breadth of Computer Science and to expose them to a wider range of knowledge and skills that could be applied to the problems they would encounter in their future careers.

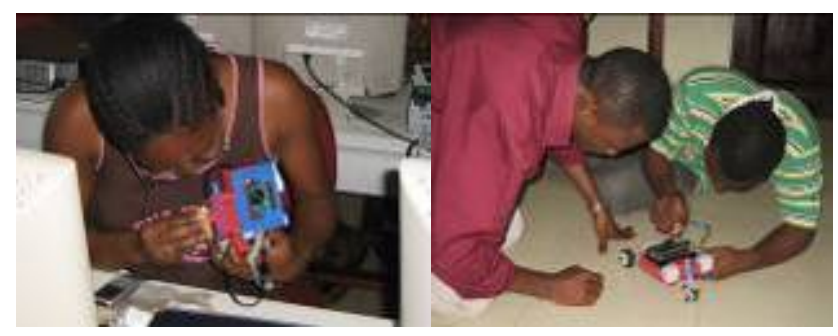

Figure 2: Ashesi students working on a project

\section{A. Infrastructure and Preparation}

One of the networked computer laboratories at Ashesi University was converted into a robotics lab for the duration of the course. Students had access to this lab for limited (but long) hours on week days and some weekends. Ashesi was not equipped with electronic or mechanical laboratory facilities or tools, hence, relevant tools and components were purchased to create a small electronics lab for this project and improvisations were made as needed. The initial offering of the course had seven participants: six men and one woman drawn from the $3^{\text {rd }}$ year and $4^{\text {th }}$ year class levels. Their previous relevant coursework included Java programming, software engineering, databases, and operating systems. The robotics course used a Lego robot mechanism with a MIT Handy Board, programmed in Interactive $\mathrm{C}$ on Linux, for the computational platform. A CMU-Cam was used for vision. Costing about US\$750 per kit, this platform was chosen based on capabilities and budgetary constraints.

\section{B. Introduction to Robotics and Artificial Intelligence}

The class met three days a week for nine weeks with lectures each morning and labs each afternoon. The first week of the course covered an introduction to robotics, an overview of Linux, programming in $\mathrm{C}$, and basic electronics. Subsequent lectures were on mobile robot kinematics, control, sensing, path planning, machine learning, machine vision, manipulation, and team coordination. Students completed four tasks and three short quizzes during the first five weeks of the course, and a final project in the last four weeks. The bulk of each task was a hands-on activity designed for teams of two or three students. Their first task was to build a machine to deliver a small ball to a goal using materials locally available within a very small budget. Students utilized plywood, bicycle parts, cans, motors, and rope, among other materials for this assignment. The next three tasks required students to construct a Lego robot, program it to execute basic motion patterns, add sensors to allow navigation through a maze, and implement a wave-front planning algorithm to navigate an environment with obstacles.

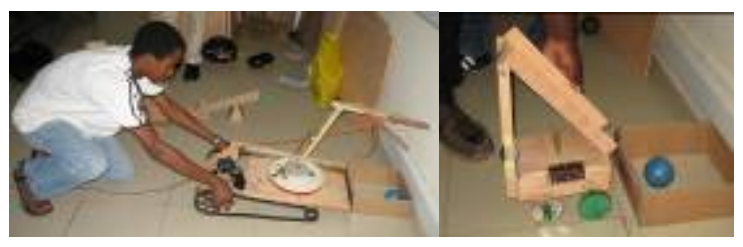

Figure 3: Building machines from local materials

The final projects, designed according to individual interests and capabilities, included navigation in a changing environment using repeated $A^{*}$ searches, mapping of an unknown environment using sonar, vision-based estimation of traffic density at an intersection, and the development of a robot that played Tic-Tac-Toe with a human opponent. Students presented their work to colleagues and friends at a poster and demo session at the end of the course.

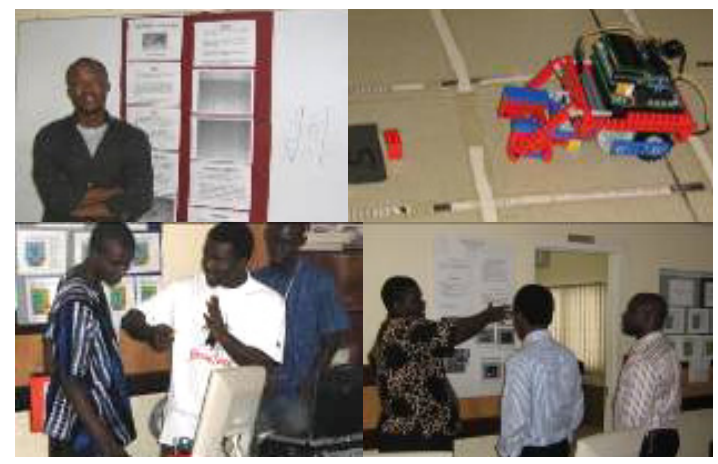

Figure 4: Ashesi students presenting at the poster session

\section{DISCUSSION}

The students in both cases found that the courses challenged them greatly. Beyond technical knowledge, they learned about system development and the intricacies, frustrations, and joys of working with hardware and software integration. They grasped the importance of practical applications based on an appropriate theoretical foundation, the inevitability of sensor noise and motor limitations, and the value of testing.

\section{A. Similarities and Differences}

Common strategies in the two courses included changing team composition for each task, requiring individual final projects chosen by the students (with instructor advice), and 
having a concluding poster session. The poster session was a great success in both courses, and resulted in increasing the confidence of the students when they realized their level of accomplishment and impressed their audience. In both courses, the instructors' concerns of some students dominating assignments were alleviated by requiring both team and individual assignments, and by assigning a large percentage of the course grade to the final project. Since these projects were implemented individually, the students' knowledge and skills were best assessed through their performance in the implementation, demonstration, written report, oral presentation, and poster presentation of their final project. Their performance in homework and lab assignments, quizzes, and class participation also contributed to their final assessment.

In addition to these practical aspects, the courses shared the following educational goals which are useful guidelines for designing a similar course:

Encourage creativity: Assignments encourage students to be creative problem-solvers as well as technology experts.

Use local resources: Courseware is designed to maximize the use of local resources, thus making the courseware more accessible and affordable to local communities. In the context of Qatar this was less of an issue since budgetary constraints were less limiting. Hence, the course provided students with the opportunity to explore local applications of CS rather than focusing on locally available resources.

Inspire with examples of state-of-the-art: Lectures and assignments inspire students with examples of the state-ofthe-art in theory and application of computing-technology.

Encourage a broad understanding: Courseware encourages students to appreciate the breadth of computing technology and its potential impact both in a local and global context.

Teach technical skills: Lectures and assignments emphasize understanding, developing, and applying technology.

Teach dissemination skills: Dissemination skills are vital to promoting successful technology leaders. Thus, courseware includes lectures and assignments to promote effective reading, writing, listening, and presentation skills.

Impact involving local community: A key goal of these courses is to encourage creative thinking and problemsolving that is relevant to the local community. Thus, assignments are inspired by locally-relevant problems and indigenous resources, and students are provided with opportunities to present their work to the local community.

Despite their many similarities, the two courses were not identical. The CMU-Q course had a longer time frame and access to more monetary resources than the Ashesi course. Thus, the robot platforms and the ratio of students to robots were significantly different in the two courses. Student preparation was also different since the Qatar students were in their second year, and thus had taken fewer computer science and mathematics courses than the students in Ghana. Concerning the class size and the gender distribution of the class, the Qatar course had more students, and the women outnumbered the men in the class, in contrast to the Ghana course, which had only one woman student. An additional challenge in the Qatar course was to allow sufficient flexibility for students to respect cultural practices in terms of mixed-gender teams, while still requiring different team compositions for each assignment.

\section{B. Course Evaluation}

At the end of each course, a variety of written and oral surveys were employed to evaluate their impact. In the Ashesi course, about half of the student exit surveys indicated that students initially thought of robotics solely in terms of humanoid robots but that the class dispelled this notion by exposing them to the breadth of the field. All the students felt they had gained technical creativity, citing ideas for novel applications and improvisation skills as examples. Some students indicated that the class inspired them to take additional related courses, explore the possibility of graduate education in robotics, incorporate some of the newly learned algorithms into future tasks, and focus more effort on testing in development. Suggested improvements to the course include repeating the task to build a machine out of locally available materials at the end of the course, placing a greater emphasis on the mathematics and physics requirements of the course, and focusing more on AI and its applications.

At CMU-Q, all students rated their knowledge gain through the course very highly. The students felt a sense of accomplishment and independence after completing different assignments, especially their final projects. Several students were motivated to further explore topics introduced in the class. An informal survey of the class revealed that a high percentage of the students had never built anything before they were tasked with assembling a robot in class. Thus, the first lab assignment was especially empowering for many of the students. Additionally, students were excited about their ability to "write a program from scratch" and to discover their ability to research new topics, understand them, and implement them. The poster session was a tremendous success where parents, faculty, colleagues, and students agreed that the students had acquired not only technical skills, but also dissemination and critical thinking skills. Suggestions for improving the course include improving the robotic platform which had many failures, including more exercises to build programming skills at the beginning of the course, and adding teaching assistants to the course.

Overall, students, faculty, and colleagues deemed both courses successful, and the two universities will continue to teach the courses in future years.

\section{LESSONS LEARNED}

Through the collective experiences of these two case studies, many important lessons are learned that can greatly benefit educators who undertake technology education in similar contexts. While the technical content of the two courses was similar to what would be taught in many 
introductory robotics courses, some key differences in teaching these courses in emerging technology regions are:

Student recruitment: Because of the novelty of the subject, more effort needs to go into advertising that highlights the relevance of the courses in order to attract students.

Fostering innovation and emphasizing breadth: Since computer science (CS) activity is a new endeavor, there are few local CS alumni and as such, little connection to the history of CS development. This makes it challenging for students and the community to appreciate and understand how new computing-related technology gets developed. Extra effort needs to go into bridging this gap. Furthermore, because local CS infrastructure (that is, the products of CS research) is in the early stages of development, it is useful to spend time discussing the potential and breadth of the field.

Making connections to career choices: It is useful to have in-class discussions that engage students in the exploration of CS careers and the potential application of CS and robotics in the local and global community. Relevant topics include discussions about local industries and the potential impact of technology on these industries, and also an introduction to professional CS organizations, conferences, and publications.

Confidence-building: Due to the limited number of local CS role models, there is a need to build confidence that state-of-the-art CS technology can be accessible in and made relevant to the local context.

Relationship-building and negotiation: Building ties with the local community is important to bolster support for the study of robotics. In some cases, establishing longer hours of access to labs and negotiating workloads with family and social responsibilities is new territory.

Entrepreneurism: A significant entrepreneurial attitude is required to both teach and study robotics in these settings. Instructors and students have to be willing to take risks and to find creative solutions to problems.

Providing research/project opportunities: With few ongoing CS research activities, such courses are often a student's only opportunity to work on robotics projects. This is in contrast to regions where students have opportunities to participate in research projects outside of class and thus build on the knowledge gained in class. A good course design should thus provide in-class opportunities for the creative use of technical knowledge. For example, having student-designed projects, rather than a fixed final project for the entire class, requires more work from the instructor, but motivates good students to experience research and become creative in using technical tools to solve problems. This helps students overcome the mental block that makes them think that they cannot develop new technology, and was a highly successful strategy in both courses. In Qatar the final project gave the students a feeling of ownership of their accomplishments and a means of exploring the breadth of technology in the robotics field applied to a local context.
Ensuring sustainability: To ensure sustainability, it is useful to have an easily accessible set of course resources geared at CS faculty who are not necessarily roboticists. These resources should include integrated, hands-on activities, as well as recommendations for locally available materials relevant to the implementation of the curriculum. Furthermore, a plan to support curriculum and resource development is also necessary to sustain any robotics education program. This could include seminars, journal subscriptions, and opportunities to attend conferences.

Other lessons learned are generally applicable to undergraduate robotics education in a variety of settings:

Utilizing experience-based learning: Hands-on projects develop the students' problem-solving abilities by reinforcing abstract concepts with concrete experiences.

Providing presentation opportunities: An important component of both courses was the poster session, which ended in great success and provided a tremendous boost in confidence to the students as they completed the course. In general, it is valuable to provide the students with an opportunity to share and reflect upon what they accomplished with friends, family, faculty and others.

Minimizing Frustration: Although some amount of frustration is unavoidable when building and testing real robots and learning to handle this is an important lesson to be taught, frustration should ideally be balanced by a sense of accomplishment when the task is completed successfully. Frustration can be minimized by carefully reviewing and testing tasks before they are assigned.

Controlling class size: Having individual final projects is very motivating for the students, as it enables them to explore individual areas of interests and further develop their strengths. In the two courses, this was successful since the small student-to-instructor (less than 10:1) enabled significant guidance in the design and execution of projects.

\section{BROADER IMPACT}

We now examine the impact on the students and community of these two courses in the period since they were taught.

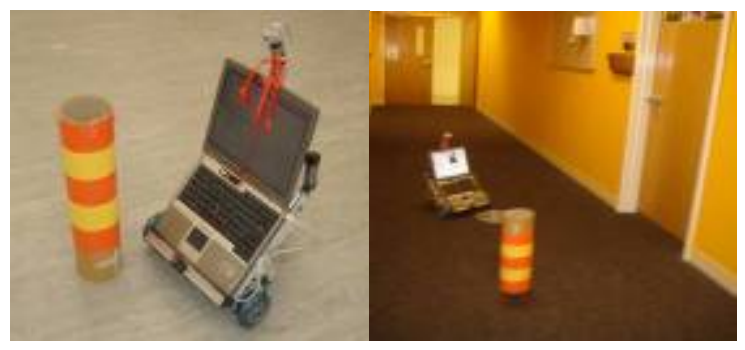

Figure 5: Mishwar, the tour-guide robot

\section{A. Broader Impact in Qatar}

A direct impact of the Autonomous Robots course, was the participation of one of the students, a co-author in this paper $^{1}$, in the first independent study at CMU-Q. An

\footnotetext{
${ }^{1}$ The co-author Noura El-Moughny
} 
independent study, in this context, is a formal course in which a student works on a research project with a faculty advisor for credit. The independent study built upon the coauthor's final project from the course: to build a tour guide robot. Figure 5 shows the robot Mishwar, meaning to "take a walk" in Arabic, giving a tour with the visual fiducial used to mark its way. The robot travels down the corridor describing who works in each office in both English and Arabic using the fiducial as an identifier for a doorway.

The idea of the tour guide robot was born from the student's experience as an orientation counselor, where the need for giving tours in both English and Arabic, and making these tours interesting was an important need. Mishwar was thus designed to enhance the level of interest of the tour and thus the accessibility of part of the campus environment. It was an example of a student-motivated project to apply robotics technology to a local problem.

\section{B. Broader Impact in Ghana}

The Ashesi class is also having a broader impact in a variety of ways. One student chose a class project that related to his final year thesis on modeling vehicle traffic. His robotics project was on estimating traffic density at an intersection by counting vehicles using a camera. He is presently extending the vehicular traffic model for controlling traffic lights to incorporate a camera as well as learning algorithms. During the course, the co-authors delivered a talk entitled "Robotics: Encouraging Creativity in Problem Solving" to industry representatives and the general public. The goal was to generate awareness of the potential for robotics technology and education to a developing economy. There was good attendance, and positive feedback. Following the pilot run of the course, the university has received requests from some industry representatives and students of other institutions for the course to be offered again and opened to the public. Some requests also seeked opportunities to work on robotics projects with Ashesi University faculty. The mentor of a secondary (high) school robotics group in another town in Ghana has also expressed interest in collaborating with Ashesi. As a result of this varied interest, Ashesi University will continue to teach the robotics course.

\section{Beyond the Case Studies}

Online access to computing-technology courseware is available via several online resources. However, many of these sites provide access to courseware designed for developed communities where technology applications are ubiquitous and where access to computers and relevant resources is made relatively easy. We are addressing this problem by developing an online course repository to disseminate courseware designed to be relevant to communities where access to technology and/or financial resources are scarce, and where the role of technology has not yet been defined in the community. Secondly, we are adding mechanisms to link students from these communities to professional organizations such as the IEEE and AAAI. Lastly, we are working to provide opportunities for students and faculty in these communities to participate in international technical conferences to interact with other technologists and disseminate their work globally.

\section{CONCLUSIONS AND FUTURE WORK:}

In this paper we present two case studies of robotics education programs; one in Qatar and one in Ghana. We have contributed lessons learned, and have examined the broader impact of these courses. In our future work, we will continue to teach these courses and to make our course material available on-line to other educators. We also hope to study the impact of these courses in a more quantitative manner over an extended period of time to better quantify the effect of different course components.

\section{ACKNOWLEDGMENT}

The authors acknowledge the support and contributions of the administration, faculty, students, and staff at Carnegie Mellon University campuses in Pittsburgh and Doha, and at Ashesi University. The work described here would not have been possible without the support of Sarah Belousov and Malcolm Frederick Dias from TechBridgeWorld at Carnegie Mellon University, Patrick Awuah, Ato Yawson, and Aelaf Dafla from Ashesi University, and Charles E. Thorpe, Mohamed Dobashi, Roman Mitz, Stephen MacNeil, and Wafa Abu Fowl from Carnegie Mellon University in Qatar.

\section{REFERENCES}

[1] A. Mukherjee, "Build Robots Create Science - A Constructivist Education Initiative for Indian Schools", Proceedings of Development by Design, Bangalore, India, 2002.

[2] Ashesi University, www.ashesi.edu.gh

[3] Autonomous Robots course, http://qatar.cmu.edu/cs/16200/

[4] Introduction to Robotics and Artificial Intelligence, http://www.ashesi.org/ACADEMICS/compsci/robotics.html

[5] J. Sachs, "Science, Technology \& Poverty: Five Ways to Mobilize Development in Low-income Countries," IAEA Bulletin, Making a Difference, Volume 44, Number 1, 2002.

[6] M. B. Dias, G. A. Mills-Tettey, and J. Mertz, "The TechBridgeWorld Initiative: Broadening Perspectives in Computing Technology Education and Research", Association of Computing Machinery (ACM) special proceedings of the International Symposium on Women and ICT: Creating Global Transformation, 2006.

[7] M. B. Dias, G. A. Mills-Tettey, and T. Nanayakkara, "Robotics, Education, and Sustainable Development", IEEE International Conference on Robotics and Automation (ICRA), April 2005.

[8] U. S. Pawar, J. Pal, and K. Toyama, "Multiple mice for computers in education in developing countries," IEEE/ACM International Conference on Information \& Communication Technologies for Development, 2006.

[9] Carnegie Mellon University Qatar, http://www.qatar.cmu.edu/

[10] Qatar Foundation, http://www.qf.edu.qa/

[11] M. Rosenblatt and H. Choset, "Designing and implementing hands-on robotics labs," IEEE Intelligent Systems, Volume 15(6), 2000.

[12] B. A. Maxwell and L. A. Meeden, "Integrating Robotics Research with Undergraduate Education," IEEE Intelligent Systems Magazine, 2000.

[13] M. Stein and K. T. Sutherland, "Sharing Resources Over the Internet for Robotics Education", American Society for Engineering Education, Middle Atlantic Section Regional Conference, 1999.

[14] TechBridgeWorld: www.techbridgeworld.org 